\title{
EL DISCURSO DEL MORIR \\ Testamentos de primera mitad de siglo XVIII en Santa Fe colonial *
}

TERESA SUAREZ *

Entre los factores estructurantes del individuo en la vida diaria, está la idea coercitiva de su limitada temporalidad. La captación de que la biografía personal es un fugaz punto del devenir cotidiano por las sociedades humanas, las ha llevado a elaborar representaciones simbólicas que rompan con la muerte biológica y la superen. Es en este plano de la cultura, que contamos con rituales, ceremonias, discursos, normas, producidos en los diferentes niveles sociales y en diferentes épocas.(1)

Estas prácticas están fuertemente estructuradas, de modo que los individuos nuevos de una sociedad las van incorporando pasivamente, con pocas posibilidades de innovar, o si lo hacen, es en planos informales, no normados, que dan rienda suelta a expresiones en cierto modo transgresoras. Así, podemos verque operan dos planos diferentes: uno relacionado con ideas, palabras, normas, que está más identificado con las élites del grupo social; $y$ otro con gestos y prácticas que van surgiendo a nivel popular, y que frecuentemente son motivo de censuras sociales $y / 0$ institucionales. Por esta razón de la fuerte estructuración, es difícil percibir los cambios históricos respecto de la conciencia de la muerte, sus manifestaciones, de modo que ello conduce a exploraciones en el tiempo largo. A los fines de ordenar este trabajo, introduciremos algunos aspectos de Santa Fe colonial en el siglo XVIII, y luego analizaremos el tema de la muerte a través de las fuentes con que contamos. Estas reflexiones tienen que ver con nuestro conocimiento previo de la sociedad colonial y con las lecturas de la historiografía existente.

- Este trabajo contó con la colaboración de Laura Lorenzón y Mariela Schanz, becarias bajo mi dirección, quienes realizaron parte del trabajo empírico.

*Universidad Nacional del Litoral. 
Fundada en 1573, la ciudad de Santa Fe se mudó de sitio en 1661 al lugar que ocupa actualmente. Como población situada en los márgenes del Virreinato del Perú, sin recursos mineros, con actividad pastoril pero constituyendo principalmente una posta de intercambios mercantiles, facilitó la conformación de un pequeño grupo de mercaderes dueños muchas veces de estancias ganaderas. La actividad política estuvo expresada en el Cabildo, que junto a la Iglesia regular (cuatro comunidades), y secular, constituía la representación local del gobierno colonial. Los actores de estas funciones eran los vecinos de mejor posición, o sea los miembros de las familias mercantiles, quienes a su vez habian legitimado su condición hidalga defendiendo la ciudad, con sus propios recursos, de los ataques indígenas. Entre 1700 y 1720 , la agresión de los indios provocó una emigración muy elevada. Corroboramos esto en la discontinuidad einterrupción de la documentación tanto civil como religiosa. El segundo cuarto de siglo, en cambio, comienza a mostrar un crecimiento importante, tanto en actividad económica como en pobladores. Es visible, sin embargo, que los forasteros fueran más propensos a ocupar temporariamente la ciudad, que a radicarse en forma permanente, excepción hecha de familias ya consolidadas en otros lugares, que por interés comercial se instalan en Santa Fe. La morada temporaria de la población flotante, predominantemente masculina, se vincula a altos porcentajes de natalidad ilegitima.(2)

Esta realidad socioeconómica se refleja en los testamentos, documentos privados identificados prioritariamente con el sector español de la sociedad. En efecto, aunque en las cartas de libertad, se da a los favorecidos "poder y facultad para que pueda tratar y contratar, hacer testamentos y codicilos, poderes para testar...y todos los demás actos que personas libres y no sujetas a servidumbre",(3) no encontramos miembros de los grupos subalternos en este período, salvo Philipe Chapa, de condición indio.(4)

El testamento se compone del nombre del testador, la profesión de fe -su pertenencia a la Iglesia-, el acto de encomendar el alma a Dios, la elección de sepultura y ceremonia mortuoria, la legitimidad y condición matrimonial, bienes y deudas, nombre de albaceas y herederos, la voluntad de anular otros testamentos y codicilos, la identidad y firma del escribano y demás testigos. Los doscientos testamentos de la primera mitad del siglo XVIII no están regularmente distribuidos por lo que dijimos más arriba, la mayor parte de ellos pertenece al período 1730-1750. Además de los testamentos, analizamos Actas de Defunción, Inventarios de bienes, y la Visita General del Obispo de Buenos Aires en 1764, que proporciona una buena evaluación retrospectiva.(5)

Con este trabajo sobre Santa Fe, proponemos ir dando a conocer los hallazgos y conclusiones para cotejarlos con otros que reúnan este tipo de percepciones. Así como aparecen modelos coloniales de pareja y familia, también hay "modelos de morir". Conocerlos permitirá profundizar en el siglo XVIII de la colonia rioplatense. María Isabel Seoane publicó un trabajo denominado Sentido espiritual del Testamento Indiano tomando como fuentes testamentos de Buenos Aires, Córdoba, Salta y 
Mendoza. Se trata de un estudio empírico que tiene por objeto destacar el contenido testamental que la secularización de siglo XIX suprimió. Muestra cómo el Derecho presta su forma para instrumentar la fe católica.(6)

La historiografía sobre este objeto de estudio, toma el tema de quienes a mediados de siglo $x x$ se habian detenido en las manifestaciones artisticas y literarias, especialmente Tenenti y Huizinga.(7) Philippe Ariès, Michele Vovelle, Pierre Chaunu, Daniel Roche, Roger Chartier, entre otros, emprenden en la década del '70 distintos abordajes y por ende contribuyen desde direcciones diversas a iluminar sus respectivos objetos.(8) Ariès y Vovelle son quienes tienen trabajos de mayor envergadura centrándose en Francia y el occidente europeo. El primero, indagando en documentación comprendida entre los siglos XIII y XX, identifica un "sistema" de la muerte en la civilización occidental.(9) El segundo, marca un hito iniciando el trabajo serial con el análisis de más de 20.000 testamentos.(10)

Mitre Fernández, en la década siguiente, observa que la Iglesia católica fue imprimiendo, desde el siglo XIV, su propia lectura de la muerte, tratando de crear un único modelo y procurando neutralizar lo folklórico popular.(11) Para un período posterior, también Daniel Roche explora cómo la Europa cristiana difunde las ideas postridentinas. En La Memoire de la mort Roche estudia el lugar que las "artes de la muerte" ocupan en la literatura francesa de los siglos XVII y XVIII. Encuentra que progresivamente hay una mayor intelectualización, un triunfo de las palabras sobre la imagen. Roche cuantifica los materiales literarios: los Manuales de prácticas piadosas constituyen el $65 \%$ hasta $1650,73 \%$ hasta $1700,80 \%$ en el siglo XVIII. Cuando investiga quiénes son los autores ve que la mayoría son católicos seculares: de cada 100 autores entre 1600-1750 (período de la difusión tridentina), el $7 \%$ son protestantes, el $8 \%$ laicos, el $17 \%$ católicos regulares y el $68 \%$ seculares. También sepregunta quién es el público de la devoción mortuoria: el episcopado; los hombres de la justicia; otros lugares: la corte, casa de los abogados, casa de mercaderes, la ciudad, el campo.

Para Roche, prepararse para morir implica un aprendizaje. En la formalización de gestos triunfa el espíritu de método, la intelectualidad del manual, la racionalidad del tratado. En ellos están las palabras y los gestos del nuevo discurso.(12)

¿Qué relación tienen estas evaluaciones con las evidencias halladas para Santa Fe? En una sociedad, como vimos, de escasos recursos económicos, la práctica de "otorgar testamento" no lleva por principal fin la transmisión de los bienes. Aun cuando se enumeran pertenencias cedidas a los herederos, el texto de los testamentos está en más del $50 \%$ destinado a las invocaciones religiosas, al ritual mortuorio, la sepultura y a los sufragios por el alma. Efectivamente, hay maneras de pensar y representar la muerte enseñadas por la Iglesia, y reminiscencias culturales de otro origen que se revelan, como veremos, a través de la Visita del Obispo.

¿Cómo se imponen y difunden las prácticas funerarias? Las decisiones del Concilio de Trento (finalizado en 1563), que dispusieron pautas ordenadoras de la sociedad como registros de bautismos, matrimonios, defunciones, normativa matri- 
monial, también atendieron el tema de la muerte.(13) Uno de los principales objetivos tridentinos: recalcar las formas del culto de la muerte específicamente católicas, se propone claramente en la iconografía; la intención es fortalecer la conciencia de la fe católica y despertar la devoción. La orden más influyente en la enseñanza fue la Compañía de Jesús.(14) Respecto de las prácticas piadosas se visualiza una piedad popular postridentina manifiesta en procesiones y peregrinaciones animadas por hermandades y cofradias. Surge una marcada devoción por la virgen, introducida y propagada también por los jesuitas. Se difunden hermandades de oración, devocionarios privados y estampas piadosas. Chaunu acuerda con esto y ve que, después de 1670 , hay un cambio en el testamento, se pasa de una posición cristocéntrica, a una mayor devoción por María.(15)

En Santa $\mathrm{Fe}$, la posesión personal de objetos litúrgicos estuvo ampliamente difundida. Esto puede verse en diversa documentación, valga como ejemplo la carta dotal de Doña Juana de los Ríos Gutiérrez, que comprende: imágenes de bulto de Nuestra Señora de la Encarnación, con corona de plata, dos niños Jesuses, un crucifijo, una Concepción de oro engastada en perlas y esmeraldas, un Santo Linun Cruziz con su nicho de plata con varias reliquias adentro, un Agnus Dey, una lámina de Nuestra Señora de la Encarnación, un crucifijo romano, un bulto del Señor Jesucristo.(16) En todos los inventarios aparecen al menos dos imágenes de bulto, láminas de Santos, crucifijos y otros objetos. En el testamento de Don José de Ruizola se lista, además, "un libro de diferencia entre lo temporal y lo eterno".(17) Un caso curioso lo constituye unaEscritura de Donación de una cruz de madera de Doña Juana Alvarez a María Magdalena de Zalazar, que "pormuchos años la vistióy adornó por la gran devoción que tiene y se debe tener al Santo Arbol de la Cruz".(18)

Respecto al crecimiento simultáneo de prácticas piadosas y superstición, podemos confirmarlo en las recriminaciones del Sr. Obispo de Buenos Aires (que visitó la ciudad en 1764), a los sacerdotes, por no controlar actividades reñidas con lo dispuesto sobre la muerte. Por ejemplo anatematiza que en los velorios de difuntos los vivos "gasten las noches en juegos y borracheras", que concurran "lloradoras lamentatrices mulatas que gritan de estudio" (atribuye esto último a la costumbre de los indios de alquilarlas a ese fin), que ante la muerte de párvulos "se empleen varios dias y noches en bailes y escandalosos fandangos", entre otras prácticas.(19)

El Concilio de Trento, introdujo nuevamente el sacramento de la Santa Unción (afectado porla oleada protestante) entre los administrados a la hora de la muerte.(20) En la mencionada Visita, el Obispo se lamenta que muchos enfermos mueran sin sacramentos; pide a los curas que amonesten a los feligreses para que "sintiéndose enfermos, con calentura continua avisen para que puedan confesarse y disponerse para el Santo Viático..., que los padres de familia soliciten lo mismo para sus hijos y domésticos que llegaren a ocho años...que se debe administrar el viático y no sólo la extremaunción". El Obispo recrimina la prioridad que se hace de la atención al cuerpo. Así, exige que se ponga cuidado en hacer testamento y solicitar la "gracia del bien morir", de la misma manera que se solicita médico y medicina para "la 
temporal salud".(21)

La historiografía observó que las convicciones sociales respecto del premiocastigo a recibir después de la muerte, no fueron siempre las mismas. En efecto, Mitre Fernández ve la utilización del infierno como instrumento de dominación ideológica.(22) En Santa Fe, en cambio, predomina un discurso esperanzado en el premio que depara la eternidad, mientras que el infierno es sólo esporádicamente mencionado. Un texto excepcional por su contenido aparece en 1682 cuando el Obispo de Buenos Aires, por entonces Antonio de Azcona, despacha censuras y excomuniones contraquienes oculten bienes pertenecientes a Santiago de Mollinedo, deudor de varios vecinos y refugiado en el convento de Santo Domingo. Ordena al cura rector que, en misa del domingo y fiestas de guardar, maldiga con las maldiciones siguientes:

"Malditos sean dichos excomulgados de Dios y de subendita Madre, Amen. Huérfanos queden sus hijos y sus mujeres viudas, Amen. El sol les oscurezca el dia y la luna de noche, Amen. Mendigando anden de puerta en puerta, Amen. Las plagas que Dios envió sobre el reino de Egipto vengan sobre ellos, Amen. La maldición de Sodoma y Gomorra que sobre los que por sus pecados tragó vivos la tierra tengan sobre ellos, Amen, con las demás maldiciones del salmo deus laudem meam me la cuereis, y dichas las maldiciones lanzando las candelas en el agua diga: asi como estas candelas mueren en esta agua, mueran las ánimas de los dichos excomulgados y desciendan al infierno con la de Judas, Amen".(23)

Esto nos sugiere la prolongación de una práctica que no es cotidiana, pero que el Obispo, tal vez molesto porque un sector de la misma Iglesia es el que lo desafía brindando amparo a Mollinedo -la comunidad de dominicos- la muestra aún vigente.

Podemos ver que la maldición se dirige en primer término a la vida de los destinatarios, y luego se prolonga a las "ánimas".

La aparición del alma está cronológicamente identificada por la historiografía. Mitre Fernández muestra que los escolásticos crearon el alma (las escrituras sólo hablaban de la resurrección del cuerpo), pero aunque la vida se prolongue en el alma después de la muerte del cuerpo, se teme por su condenación en el infiemo. La difusión del purgatorio en los 1600 atenúa el miedo a la condenación.(24) La nueva instancia del purgatorio contradice el principio de la salvación por las propias obras: son las oraciones de los vivos las que hacen posible la salvación.(25) El Obispo De la Torre en la Visita a Santa Fe, revela el objeto de la voluntad testamental respecto alcuidado del alma, de lo que deberán ocuparse los familiares: el Obispo pide enterrar el difunto con Misa de Requiem, de lo contrario "se acaba su memoria con la sepultura". Este hecho no está dirigido sólo al muerto y su alma, sino a los vivos, quienes ordenando misas por el difunto ganarían una suerte deindulgencia: "...siendo cierto que la oración vuelve y cede en utilidad de quien la hace", el Obispo espera que "no falten personas acomodadasy devotas que con estas espirituales usuras quieran utilizarse".(26) 
Hay, en síntesis, dos horizontes de salvación: se apela a salvación con las invocaciones a la virgen intercesora, al santo del nombre, a la corte celestial, abogados intercesores a los que podríamos denominar intangibles. Sebusca también una salvación desde abajo, desde lo terreno, es la que protagonizan albaceas y familiares. El alma es heredera: da ilusión de continuidad porque los bienes sostienen las oraciones. Don Luis Rivero Raposo, da la mitad de sus bienes a sus herederos, y la otra mitad "se aplicase al bien de su alma".(27) Estos bienes erancuantiosos, pero también los hay modestos: Doñalsabel de Paez, en una carta de cesión de intervivos, cede un cuarto de solar a su sobrino clérigo "para que diga $\mathbf{4 5}$ misas rezadas por el bien de mi alma".(28) "En provecho de mi alma", "por el bien de mi alma", "por la salud de mi alma", "en sufragio de mi alma", son expresiones comunes acuñadas en los testamentos.

Los historiadores localizaron el miedo a la muerte en diferentes tiempos: para Ariès, la muerte natural, que provoca indiferencia es medieval, mientras que el miedo es propio de la edad moderna.(29) Vovelle duda del "no miedo medieval" y con él acuerda Mitre Fernández, quien al final de su libro se pregunta, ¿es la muerte vencida o es vencedora? Probó que el miedo a la muerte no fue producido por las pestes y hambrunas de mediados del siglo XIV, sino que ya estaba presente antes en la sociedad.

Desde la documentación que manejamos en Santa Fe interpretamos algunos signos como posibles manifestaciones de miedo. Por ejemplo:

- Se evita la utilización de la palabra muerte. Los testamentos dicen "...cuando la voluntad de Dios me lleve de la presente vida", "...al final de mis dias...", "...si Dios me llevase..." Cuando está la palabra muerte, en cambio, tenemos esta expresión: "...temiéndome de la muerte tan natural a los hombres y deseando poner mi alma en camino de salvación..." o bien en la invocación "...cuando mi alma de este cuerpo saliere porque como verdadero católico protesto vivir y morir en la fe..."

- El miedo a la descomposición del cuerpo se evita cubriéndolo con una mortaja, a elección, que identifica las preferencias hacia un santo pidiendo ser vestido con su sayal, o bien con una mortaja común.

- Los donativos a la Iglesia, muy diversos en sus montos, pueden haber sido motivados por miedo, a cambio de salvación, o bien para destacar la propia "condición". El testamento es un lugar más para mostrar la calidad, no sólo "vivir de acuerdo a su condición", sino también "morir". Limosnas, mandas forzosas, obras pías, capellanías, bienes personales para decorar los altares, el lugar de sepultura, muestran el sitio del muerto en la sociedad. El otorgamiento de capellanlas se hace, por lo general, para el que testa y para sus familiares, aun los ascendientes -además de los descendientes- y no sólo los de "sanguinidad" sino también los de afinidad. Piezas de esclavos, casas, plata y otros bienes pasan a la Iglesia por este concepto. Los capellanes propietarios más favorecidos en las familias donantes son los que se aplican al estado clerical, los varones y los herederos mayores; así, el orden, el sexo y la edad forman parte de la jerarquización. 
El costo de los servicios fúnebres, más de 50 pesos, parece muy elevado comparado con los valores de la mano de obra, la vivienda, el ganado. Sin embargo, los privilegiados de esta sociedad consideran importante hacerlo. Dicho costo no sólo implica el donativo a la Iglesia, sino también incluye el luto, como se evidencia en el registro de gastos del funeral del General Don José de Ruiezola:

Primeramente a San Francisco por entierro y funeral como consta en el recibo del Padre Guardián, 209; a Santo Domingo, 11; a la Merced, 12; para la Cruz y lo demás del entierro, 72; a los clérigos, 30; por la mortaja de Nuestro Padre San Francisco, 25; de los lutos para los sirvientes del difunto, 30; de cera para el funeral, 30; de mandas forzosas, 2; de luminarias, 2; la hechura y forro del ata d, 8; Total, 431 reales.(30)

Los miembros de las Ordenes Terciarias pidieron ser sepultados en los respectivos conventos "...al pie del altar que erigí en su honra y gloria de Nuestra Sra. de Regla, San Lorenzo y San Vicente...en la Capilla Mayor, al lado de la Epistola, cuyo entierro y propiedad no sólo es para mí y mis herederos de sanguinidad sino también para los parientes de afinidad".(31) Es necesario destacar quelas Invocaciones religiosas son más largas en los testamentos de quienes ocupan la cima de la sociedad.

Contrastan con estos ceremoniales, las sepulturas de pobreza. Aunque testen hay quienes expresan su condición económica: "...al matrimonio no traje cosa alguna en razón de mi pobreza...", "casé a mi hija pero no le dí dote en razón de mi pobreza...".(32) El Obispo opina, sin embargo, que muchos "se fingen pobres", negándoles entierro salvo a aquellos considerados "miserables": los que, no sólo no dejan bienes, sino que no tienen a nadie que pueda "sufrir la corta limosna del entierro".(33)

No siempre se reprime o sublima el miedo. Expresiones diferentes a los calificativos "natural" o "temida" testamentales hacia la muerte, aparecen en los textos legos. Así como Mitre Fernández destacaba "villana" de Dante y "cruel" de Petrarca, en un poema anónimo se lee:

"Traidora, infiel, tirana, venenosa, ardiente $P$ arca, vengativa, insana, detente, atroz, altiva, cruel, ufana, deudora audaz, flechera vigorosa".(34)

Calificativos que muestran sin tapujos el rechazo a la muerte.

Como hemos visto, el modelo del bien morir, comprende la recepción de los sacramentos de la Eucaristía, Extrema Unción y Matrimonio. El texto del testamento, sin embargo, no siempre menciona los dos primeros, omisión que no ocurre con la consideración delsacramento delmatrimonio, quemerece una atención preferencial. Por lo que vemos, hay una jerarquización de los sacramentos. Del total de siete, los testamentos de SantaFe prevén tres, cuya recepción permiteganarvirtudes: el orden 
sagrado y el matrimonio son instrumentos de ennoblecimiento; la eucaristía, de fortalecimiento; y la extrema unción es símbolo de triunfo.(35)

Se nota una especial insistencia en el estado matrimonial. Esto condice con el control que desde el Concilio de Trento también se impuso sobre la sexualidad.(36) Ariès asocia el sexo y la muerte en cuanto representan fuerzas incontrolables de la naturaleza, amenazan disolver el orden social, por lo tanto es necesaria su administración.(37) En los testamentos de Santa Fe el matrimonio se destaca con las palabras "fui casado y velado in fascie eclesie". El estado de castidad también es destacado: "...mi cuerpo sea amortajado con el hábito de Nuestra Sra. del Carmen que es el que he usado toda mi vida porque no he sido casada...".(38) La necesidad de la declaración de estado matrimonial permite ver en qué medida la celebración se hacía. Doña Isabel de Cepeda dice que tuvo "...cuatro hijos debajo de la fragilidad humana habidos, que declaro ser naturales y habidos en buena fe".(39) En el mismo sentido lo hace Doña María Arias de Mansilla (tres hijos naturales),(40) Doña Pascuala de Espinosa,(41) entre otras.

\section{Conclusiones}

La historiografia coincide en afirmar quehay manifestaciones culturales motivadas en los sentimientos que provoca la idea de la muerte en la sociedad. Acuerdan, además, en que los sentimientos, valores, interpretaciones variaron a través del tiempo, y por ende, sus representaciones simbólicas. Para Ariès, hay, entre los siglos XIII Y XX, cuatro períodos que no necesariamente se suceden en forma lineal, pero que representan primero, la aceptación de la muerte: la sociedad colectivamente la toma como cosa natural; en la modernidad aparece la conciencia individual y el miedo, es lo que el autor llama "la muerte propia"; aproximadamente en el siglo XVIII se percibe la muerte ajena, unido a la modificación de los lazos familiares: mayor afectividad entre los miembros de la familia. Finalmente la etapa contemporánea separa al enfermo de su familia y casa, para llevarlo al hospital; se niega la muerte: es la "muerte prohibida".(42)

Aproximadamente en la segunda etapa de Ariès, Chaunu ubica la "muerte predicación" o "muerte barroca". Ese es el modelo que reconocemos en Santa Fe, aunque se prolonga más allá de lo que Chaunu ve para Francia. Para Chaunu desde 1740 las disposiciones testamentales respecto del alma tienden a desaparecer y se limitan a disponer sobre los bienes, borrándose la piedad barroca.(43) Lawrence Stone, revisando la historiografía del tema, duda de que sea debido a la influencia secularizadora -principal argumento de Seoane- y lo atribuye a una mayor confianza del muerto en sus familiares.(44)

En Santa Fe esto parece posible: progresivamente en el siglo van apareciendo cada vez más poderes para testar otorgados a familiares, que cartas testamentales "...se lo tengo comunicado..." En los poderes aparece la solicitud respecto de la ceremonia mortuoria, la sepultura, la mortaja, mientras que las invocaciones 
religiosas son breves, y la cesión de bienes a los herederos, cuyos nombres se especifican, corre por cuenta de los albaceas.

¿Cuál es la relación entre la actitud ante la muerte y los testamentos? Estos manifiestan sólo parcialmente las percepciones del conjunto de la sociedad. Comparando el número de difuntos adultos y el de testamentos, los testadores representan sólo alrededor de un $10 \%$. Los testamentos, sin embargo, fueron adquiriendo un espacio cada vez mayor conforme a la significación que lo escrito adopta en la sociedad occidental, y se va expandiendo desde la élite hacia abajo. Modelado por la Iglesia como predicación, el testamento va incorporando, sin embargo, otras dimensiones: es un reflejo de la situación económica, de los valores de los individuos, de sus sentimientos. Aunque se confiesan las creencias adquiridas en una educación católica, el status personal y familiar se tornan más importantes que lo estrictamente religioso. Es en este aspecto que consideramos a los testamentos como una herramienta útil de análisis social.

Pensar en la muerte moviliza y pone de manifiesto otros aspectos, por ejemplo los sentimientos. ElCap. Don Juan Berón otorga a Doña Petrona de Berón un asiento de tierras "...en razón de ser mi entenada y el amor que le tengo".(45) En el poder para testar de Don Antonio Mujica a Doña María Andrea de Zevallos, su mujer, y la susodicha a su marido "...cuando la voluntad de Dios Ntro. Sr. fuese servido llevarnos de esta presente vida a la de sus escogidos, para que el que sobreviviere en días al otro dejamos poder para testar..." piden "ser enterrados en el convento de Santo Domingo, en la bóveda que allí tenemos y amortajados con el santo hábito de Ntro. Padre San Francisco, por lo mucho que nos queremos...".(46) El Cap. Juan Lorenzo Garcia Ugarte, quien se había casado con una viuda con 3 hijas y luego de la muerte de su esposa fue albacea, expresaba respecto a las jóvenes "...con el mucho gusto que me dieron en su honesto y obediente modo de proceder y el entrañable amor que por todo les tuve y de presente".(47)

Otro aspecto revelador de los testamentos, es el aprecio por el trabajo personal. En su Carta de Testamento, Doña María Guerreros dice: (nos casamos) "...sin dote ni capital y con mucha industria y trabajo personal compramos casa en medio solar..."(48) Cuando Doña Petrona Suarez Altamirano otorga bienes a su hijo Joseph expresa: "...lo mantuve y eduqué juntamente con sus hermanos vistiéndolos con mi trabajo personal y demás armas..."(49) Doña Savina de Guerreros, le deja su casa a María Rosa, su nieta "...como que fue trabajo de su padre..."(50)

La Iglesia tuvo en sus manos la salvación de sus fieles; se apropió de esta tarea. Sin embargo, podría pensarse que, la creencia en que las oraciones y misas pueden salvar, las manifestaciones extemas del ritual, y el apoyo de la comunidad de fieles, pudieron haber promovido una suerte de optimismo.

Como elemento ordenador, el testamento contribuyó al fortalecimiento de relaciones sociales: entre familiares, entre amigos, entre amos y servidores, aunque más no fuera como reconciliación a la hora de la muerte manifestada en la concesión de cartas de libertad, en un cuarto, el ajuar cotidiano. Expresó una síntesis de 
necesidades mundanas y espirituales, individuales, familiares y de la comunidad. Reveló aspectos significativos del espacio recorrido por el testador, temporal y geográfico. Mostró sus lealtades cotidianas, su pertenencia a un lugar y a su gente.

¿En qué puso su mirada el testador?: en la protección a los menores, en el respeto a lo mandado y lo prohibido. Reveló a veces la soledad, los secretos, los hijos naturales ocultos. Se revisa el pasado, los objetos intimos y personales, se traspasan los objetos de guardar, relicarios, recipientes, arcones, escritorios.

Hay quehacernotar, no obstante, que aparecen otros documentos que expresan voluntades y ceden bienes, sin ser necesariamente testamentos: cartas de dotación, cesión intervivos, poderes con decisiones expresas, cartas de donación. Si volvemos a la idea del miedo a la muerte, e implicando el testamento la idea del final de la vida, podría comprenderse que se hayan formulado otro tipo de escrituras sin augurios de muerte.

\section{NOTAS}

(1) BERGER, P.y LUCKMAN, T., La construcción social dela realidad, Amorrortu, Buenos Aires, 1986.

(2) SUAREZ, T., Sexualidad y sociedad en la colonia marginal, Santa Fe siglo XVIII, Tesis doctoral, UNLP, 1993.

(3) Carta de libertad a María Andrea, Departamento de Estudios Etnográficos y Coloniales [DEEC]. Escrituras Públicas [EP], t. XIII, f. 516.

(4) Para el período mencionado encontramos un solo testamento indígena: Philipe Chapa, DEEC, EP, t. X, f. $277,31 / 10 / 1720$.

(5) La documentación religiosa pertenece al Archivo del Arzobispado de Santa Fe [AASF].

(6) SEOANE, M. I., Sentido espiritual del Testamento Indiano, FECIC, Buenos Aires, 1985.

(7) TENENTI, A., "Ars Moriendi. Quelques notes sur le problème de la mort à la fin du XVe. siècle", en Annales, E.S.C., octubre-diciembre, 1951; HUIZINGA, J., Le Dèclin du Moyen Age, Payot,, París, 1967 -traducción francesa 1948-

(8) CHAUNU, P., "Mourir à Paris (XVle, XVIle, XVIlle siècles)", pág. 29; CHARTIER, R., "Les arts de mourir, 1450-1600", pág. 51; ROCHE, D., "La Mémoire de la mort: recherche sur la place des arts de mourir dans la Librairie et la lecture en France auX XVIle et XVIIle siècles", pág. 76.; VOVELLE, M., "Les attitudes devant la mort: problèmes de méthode, approches et lectures différentes", pág. 120; en Annales E.S.C., 31e. Année № 1, 1976.

(9) ARIES, P., El hombre ante la muerte, Santillana, Madrid, 1983.

(10) VOVELLE, M., op. cit., y Piété Baroque et déchristianisation en Provence au XVIIIe siècle. Les attitudes devant la mort d'après les clauses des testaments, Plon, París, 1973.

(11) MITRE FERNANDEZ, E., La muerte vencida. Imágenes eHistoria en el OccidenteMedieval, 1200 1348, Encuentro Ediciones, 1988, págs. 38-39.

(12) Idem. Esto condice con un trabajo de Roger Chartier, "La práctica de lo escrito", en Historia de la Vida Privada, dirigida por Georges Duby y Philippe Ariès, vol. 5, pág. 113, donde el autor destaca el lugar que la lectura y lo escrito ocupan progresivamente en Europa, sobre todo a partir de que, por la difusión del protestantismo, la libre interpretación de la Biblia lo requiere.

(13) JEDIN, H., Manual de Historia de la Iglesia, Herder, Barcelona, 1972, t. 5.

(14) Idem, pág. 776.

(15) CHAUNU, P., op. cit.

(16) DEEC, EP, t. XIII, f. 290.

(17) Idem, t. XI, f. 288. 
(18) Idem, t. XIII, f. 635.

(19) AASF, Defunciones, Visita de D. A Manuel Antonio de La Torre, Obispo de la Ciudad de Trinidad de Buenos Aires.

(20) JEDIN, H., op. cit., pág. 473.

(21) AASF, Defunciones, Visita, op. cit.

(22) MITRE FERNANDEZ, E., op. cit.

(23) AASF, Autos y Decretos, t. I, f. 9.

(24) LE GOFF, J., La naissance du Purgatoire, en MITRE FERNANDEZ, E., op. cit., pág. 26.

(25) La Iglesia militante interviene eficazmente en el proceso de purificación, liberación y expiación de las almas. Hay una acción corredentora. La existencia del purgatorio testimonia el carácter colectivo de las retribuciones finales. CONGAR, P., "El Purgatorio", en AINE, J., et al., El misterio de la muerte ysu celebración, Desdeé, Buenos Aires, 1952 -original francés: Le mystère de la mortetsa célébration, reúne investigaciones públicas, patrísticas, litúrgicas y pastorales-.

(26) AASF, Visita, op. cit.

(27) DEEC, EP, t. XIII, f. 583.

(28) Idem, f. 603.

(29) ARIES, P., op. cit.

(30) DEEC, EP, t. X, f. 306, 1720. Memoria y razón de lo que se ha gastado con el funeral del Gral. D. José de Ruiezola.

(31) Juan Lorenzo García Ugarte, DEEC, EP, t. XIII, f. 199, 1738.

(32) Pedro Cabral, DEEC, EP, t. XII, f. 43-44, 1730.

(33) AASF, Visita, op. cit.

(34) LOPEZROSAS, R., "Poetas santafesinos de la colonia y la montonera", en Revista Universidad, $N^{2} 26$, UNL, Santa $F_{e}, 1952$.

(35) MITRE FERNANDEZ, E., op. cit.

(36) SUAREZ, T., op. cit.

(37) ARIES, P., op. cit.

(38) Testamento de Doña María Josefa Suarez de Altamirano, DEEC, EP, t. XIII, f. 459.

(39) DEEC, EP, t. XI, f. 74, 1715.

(40) Idem, t. X, f. 35, 1714.

(41) Idem, t. XIII, f. 365.

(42) ARIES, P., op. cit.

(43) CHAUNU, P., op. cit.

(44) STONE, L., El pasadoy el presente, FCE, México, 1986, cap. XV "La muerte" -1edición en inglés, 1981 -

(45) DEEC, EP, t. XIII, f. 297.

(46) Idem, f. 371, 20/12/1743.

(47) Juan Lorenzo Garcia Ugarte, DEEC, EP, t. XIII, f. 199, 1738.

(48) DEEC, EP, t. XIII, f. 645.

(49) Idem, f. 374.

(50) Idem, f. 380. 